\title{
An Empirical Analysis of the Relationship Between Urbanization and Fiscal Policy --- Taking Jiangxi Province of China As an Example
}

\author{
Xiao-Ying Wan ${ }^{1,2}$ \\ ${ }^{1}$ School of economics and management, China University of Geosciences (Wuhan), China \\ ${ }^{2}$ Modern Economics \& Management College, Jiangxi University of Finance and Economic, China \\ Correspondence: Xiao-Ying Wan, School of economics and management, China University of Geosciences (Wuhan), \\ China; Modern Economics \& Management College, Jiangxi University of Finance and Economic, China.
}

Received: January 2, 2018 Accepted: January 24, 2018 Online Published: March 27, 2018

doi:10.5539/jmr.v10n2p140 URL: https://doi.org/10.5539/jmr.v10n2p140

\begin{abstract}
Urbanization is still the direction of China's development in the next twenty years. The study of the relationship between fiscal policy and urbanization is of great value to the healthy promotion of urbanization. In this paper, through the establishment of vector autoregressive model, and analysis using the impulse response function and variance decomposition empirical dynamic correlation between the development of urbanization in Jiangxi province and that of fiscal policy, fiscal policy focus; at the same time, this thesis employs qualitative analysis and quantitative analysis, normative analysis and empirical analysis, combined with the reality of the development of urbanization in Jiangxi Province in order to analyze of the relationship between the development of urbanization in Jiangxi province and fiscal policy and the existing problems. The study found that there is a cointegration relationship between fiscal policy and urbanization. The impact of fiscal expenditure on Urbanization in Jiangxi is better than that in fiscal revenue. Finally, this paper also puts forward relevant policy.
\end{abstract}

Keywords: urbanization, fiscal policy, empirical analysis

\section{Research Background and Significance}

\subsection{Research Background}

Compared with other developed countries, the development of urbanization in China has experienced a dramatic development and change. With the continuous deepening of reform and opening up, in the past thirty years, from the point of view of the rate of urbanization alone, China has been from $17.9 \%$ to $63.73 \%$ in the first year of reform and opening up. The large population base is one of the largest basic national conditions in China, so the population growth of China's urbanization is also accompanied by a huge growth rate, which is an absolute growth miracle in the world.

China's cities and towns will get faster development and expansion in the process of future development, so the demand for investment in public infrastructure and services will also increase. From this perspective, the increasing public financial input can better serve the infrastructure and related public services needed for the development of new urbanization in China, thereby enhancing the intrinsic quality of China's cities and towns and making the inherent advantages of cities and towns more effective, including the advantages of division of labor and agglomeration effect. Therefore, whether it is from the theoretical point or the practical application, it is of far-reaching significance to study the urbanization of Jiangxi from the perspective of finance.

\subsection{Research Significance}

According to the annual population change situation of Jiangxi Provincial Bureau of statistics, the survey shows that at the end of 2016, the total resident population was 45 million 922 thousand and 600, the proportion of urban population in the total population was $53.1 \%$, which was 1.48 percentage points higher than that in the previous year. From a realistic point of view, if Jiangxi province wants to achieve a sustained development in the future, the new urbanization is a huge impetus. How to make better use of the promotion of fiscal policy in this process? How to better exert the important role of fiscal policy in the effective distribution of resources, the maintenance of social justice and the relevant regulation and control of macroeconomic measures? How to better understand the financial links among the various levels of government so as to increase the channels of financing and let fiscal policy run on the track conducive to urbanization? These problems can not to be ignored for the design of the system, the implementation of the policy and the level of management in the future. 
At the same time, from a theoretical point, this paper also has a very important theoretical value. Studying and analyzing the existing problems of Jiangxi Province under the traditional urbanization mode from the financial point of view, as well as the reasons behind the fiscal policy and the mechanism of the new urbanization, which can effectively provide more theories for the new urbanization Knowledge and theory guidance.

\section{Research Review}

\subsection{Foreign Related Research}

Weber (1929) had this view: because of the development of industrialization, the division of labor was also developing. Urbanization was a response to this phenomenon in space. Scott (1970) thought that the proportion of service industry was directly proportional to the degree of urbanization development. Later, some scholars had analyzed and studied this theory. LamPard (1955) took the United States as an example, found that the faster the urbanization developed, the faster its economic developed. After a careful analysis of more than 100 countries, Renaud (1981) found that urbanization rate doubled once GNP per capita doubled from US \$ 250 to US \$1,500. When GNP per capita continued to increase, its urbanization level would be further increased. Henderson (2000) also analyzed the relationship between the level of urbanization and the average per capita in each country. Therefore, most of the scholars do empirical research on urbanization and economic development through reading foreign literature in this field. Few scholars will take the index of urbanization in rural area alone as an independent variable.

\subsection{Research on Urbanization in China}

About the research of the development mode of urbanization, Fei Xiao tong (1984) and other scholars emphasized the importance of developing small towns, which is what we usually understand "small towns will breed big problems". Wang Xiaolu and Xia Xiaolin (1999) had this view: considering the obvious agglomeration effect of big cities, China should also learn from the experience of European and American countries and put the big cities in the first place.

There are many literatures on urbanization from the perspective of finance. Ma Yuan (2010) analyzed quantitatively the three aspects of urbanization, fiscal expenditure and farmers' income in China, and found that the development of urbanization and related financial support had a positive effect on the income of Chinese farmers. Sun Wenji (2011) and other studies found that the relationship between urbanization and fiscal policy was mutually promoting and interrelated. Wang Jianwei and He Guoqin (2012) analyzed the role of financial support on the development of urbanization from the perspective of "synergistic innovation". Sun Wenji (2014) believed that in order to better promote the healthy development of China's urbanization, the establishment of financial mechanism, the adjustment of financial support structure and the improvement of related efficiency were all problems that must be solved to promote the development of new urbanization in China.

\section{Empirical Research}

\subsection{Variables Selection}

The main content of this paper is the relationship between urbanization and fiscal policy in Jiangxi Province, and explores the relationship between urbanization and fiscal policy in Jiangxi Province, so as to provide suggestions for Jiangxi's urbanization. In the selection of variables, this article refers to the practice of many documents, and enumerates the following.

(1) fiscal policy variables

The financial policy regulates the economic operation by means of tax, subsidy, deficit, national debt, income distribution and transfer payment, and so on ${ }^{1}$. When fiscal policy is used to regulate the economy, it often means "reverse business cycle". That is to say, when the economy is overheating, we should adopt a tight fiscal policy. Otherwise, we should adopt an expanded fiscal policy when the economy is depressed.

When choosing fiscal policy variables for empirical research, scholars can be divided into two categories: one is to regard fiscal policy as the background of economic operation, so that there is no quantitative index, but there is still a separation between literal description and specific time points. This measure was used by Xu Xianchun, Wang Baobin and Xu Xiongfei (2013) in the study of the relationship between investment growth and fiscal policy. They adopted multidimensional measurement of investment growth, while the measurement of fiscal policy was only separated from the time point. A certain time point corresponds to the corresponding fiscal policy of austerity or expansion judged by subjective consciousness. The benefits of this approach are clear at a glance and not overly quantitative and analytic and can clearly make the personal judgments. However, when classifying fiscal policy, it does not convince people.

\footnotetext{
${ }^{1} \mathrm{Xu}$ Xianchun, Wang Baobin, Xu Xiongfei. China's investment growth and its relationship with fiscal policy [J]. Management World, 2013, 06: 1-11.
} 
Analyzing whether China's fiscal policy is tightening or expanding during a certain period of time is too subjective. In fact, even if China's fiscal policy is positive, it is also a camera choice. It may not be the same at a certain time of the year. The classification method can not be generalized. Another method is to quantify the variables of fiscal policy using certain indicators. Liu Jinquan, Yin Yin, Pang Chunyang ${ }^{2}$ (2014) used this method when studying the effectiveness of China's active fiscal policy, and most scholars often use this method when quantifying financial policy variables. The difference lies in the choice of indicators. The variables used by Liu Jinquan, Yin Shi and Pang Chunyang are fiscal revenue and fiscal expenditure. The advantage of using this quantitative index is to avoid the author's individualized hypothesis and ensure the objectivity of the study. Of course, the reason why Xu Xianchun, Wang Baobin and Xu Xiongfei used a qualitative description was that they wanted to distinguish fiscal policy of austerity and expansion. However, in the studies of Liu Jinquan, Yin Shi, and Pang Chunyang, it was assumed that China's fiscal policy was positive for this period of time. Namely, regardless of fiscal expenditure and income, fiscal policy was expanding during the period.

And when we quantify the variable of fiscal policy, there will be different indicators. Zhu Jialiang and Zhang Yang $(2015)^{3}$ studied the relationship between the support of fiscal policy and the process of China's urbanization. In his empirical research, the index of fiscal policy variables was the government's tax revenue and government investment expenditure. Yu Hongyan (2008) studied the relationship between urbanization and fiscal policy in China. It also used the government's fiscal revenue and fiscal expenditure as indicators for measuring fiscal policy. Liu Hao (2013) also adopted her approach. The content and perspective of her research were similar.

Based on the existing literature research, taking into account the availability and authenticity of the data, the fiscal policy is measured using the Government Expenditure (FR) and government tax revenue (FE) in the statistical annual report issued by the Statistics Bureau of Jiangxi Province every year. As with other scholars on data processing, logarithm processing is performed on too large data.

(2) the variable of Urbanization level

In measuring the level of urbanization, the commonly used method is the proportion of urban population to the total population. But the statistical caliber of urban population is different, some are urban permanent population, some are urban census register population, and the number of urban employment is also used. Lei Xiaoyu, Gong Liutang (2014) studied the relation between urbanization and China residents consumption rate, taking into account the reasons of empirical methods, using the city's household population as a measure of the level of urbanization. However, in their robustness test, they used to replace the household population with the resident population. Ma Xiaoxian (2014) $)^{5}$ pointed out that the current urban water balance was only an indicator of the urbanization of the population, but not a comprehensive indicator of the level of urbanization. The level of urbanization should also include the urbanization of the economy and the urbanization of the society. So in his article, he measured the level of urbanization from these three dimensions. When measuring the level of population urbanization, he suggested that if we used the ratio of household registration to the total population, we would have an error with the index issued by the Statistics Bureau, and if we used the permanent population, we would be more unified with the index issued by the Statistics Bureau. So he used the proportion of the permanent population and the total population to measure the urbanization of the population. In addition, he used the proportion of the output value of the two or three industry as the total output value to measure the urbanization of the economy, and used the disposable income per capita as an index of social urbanization. Li Zi Lian $(2013)^{6}$ put forward the concept of coordination between population urbanization and land urbanization when studying the current situation of population urbanization and urban area in China. He thought that the urbanization marked by urban population is different from the urban area marked by urban area, and it did not agree with the urbanization.

Based on the existing literature, taking into account the availability and authenticity of data and the representativeness,

${ }^{2}$ Liu Jinquan, Yin Zhong, Pang Chunyang. Research on the effectiveness of China's active fiscal policy and the period structure of policy [J]. China industrial economy, 2014, 06:31-43.

${ }^{3}$ Zhu Jialiang, Zhang Yang. An empirical study on the relationship between urbanization process and fiscal policy in China [J]. China price, 2015, 01:32-35.

${ }^{4}$ Lei Yuyu, Gong Liutang. The effect of urbanization on residents' consumption rate: theoretical model and empirical analysis[J]. Economic Research, 2014, 06:44-57.

${ }^{5}$ Ma Xiao Xian. Analysis of the key factors and effects of urbanization in China [J]. China's population, resources and environment, 2014, 12:117-124.

${ }^{6}$ Li Zilian. The mystery of Population urbanization lagging behind land urbanization: Explanation from China's provincial panel data. [J]. China's population, resources and environment, 2013, 11:94-101. 
this paper uses the ratio of urban resident population to the total population of the city to measure the level of urban urbanization.

\subsection{Model Building}

The vector autoregressive (VAR:Vector Auto-regression) model is usually used for the prediction of the related time series system and the dynamic effect of random disturbance on the variable system. The model avoids the need for the system in each of the endogenous variables on all endogenous variables lagged value modeling function structure modeling method. In the model, all variables should be regarded as endogenous variables without distinction. The endogenous variables in the model were used to analyze some of their lag values to estimate the dynamic system of all endogenous variables. $Y_{t}$ and $Y_{t-1}$ is a three-dimensional column vector, $\beta$ Is the parameter matrix to be evaluated. $\varepsilon_{t}$ Is a random perturbation item. Elements can relate to each other but do not correlate with their own lag values and the variables on the right side of the model. To do this, VAR model is established.

$$
Y_{t}=\alpha+\sum_{i=1}^{p} \beta_{i} Y_{t-i}+\varepsilon_{t^{4}}
$$

In the model, $Y_{t}$ and $Y_{t-1}$ is a three-dimensional column vector. $\beta_{i}$ represents the matrix of estimated coefficients of order $\mathrm{p}^{*} \mathrm{p} . \alpha$ Is a constant term matrix. $\varepsilon_{t}$ is the error term of the model. Its representation is as follows:

\subsection{Stability Test}

$$
Y_{t}=\left(\begin{array}{l}
\ln F R_{t} \\
\ln U R_{t} \\
\ln F E_{t}
\end{array}\right), \quad \alpha=\left(\begin{array}{l}
\alpha_{11} \\
\alpha_{12} \\
\alpha_{13}
\end{array}\right), \quad \beta_{i}=\left(\begin{array}{l}
\beta_{1 p} \\
\beta_{2 p} \\
\beta_{3 p}
\end{array}\right), \quad \varepsilon_{t}=\left(\begin{array}{l}
\varepsilon_{1 t} \\
\varepsilon_{2 t} \\
\varepsilon_{3 t}
\end{array}\right)
$$

For the processing of time series data, it is necessary to test the stability of the data first. Only through the test of smoothness can the data be considered to be meaningful based on the analysis of time series, otherwise it is difficult to avoid the problem of pseudo regression. This paper uses the Eviews software to perform unit root tests on the three variables in the paper, using the ADF method, from general to special, step by step to test out the optimal lag order. The final result is that three variables are integrated of order 2.Test results are shown in Table 1 shown.

Table 1. Variable stability test results

\begin{tabular}{l|l|l|l|l|l}
\hline Variable & $(\mathrm{C}, \mathrm{T}, \mathrm{K})$ & $\begin{array}{l}\text { ADF } \\
\text { value }\end{array}$ & $\begin{array}{l}1 \% \\
\text { significant }\end{array}$ & $\begin{array}{l}5 \% \text { significant } \\
\text { level conclusion }\end{array}$ & conclusion \\
\hline $\operatorname{lnFE}$ & $(\mathrm{C}, \mathrm{T}, 2)$ & -1.7739 & -4.3548 & -3.5942 & unstable \\
\hline$\Delta \operatorname{lnFE}$ & $(\mathrm{C}, 0,2)$ & -3.6216 & -3.7202 & -2.9848 & unstable \\
\hline$\Delta^{2} \operatorname{lnFE}$ & $(0,0,0)$ & -5.1259 & -2.6558 & -1.9547 & stationary \\
\hline $\operatorname{lnFR}$ & $(\mathrm{C}, \mathrm{T}, 3)$ & -1.2971 & -4.3549 & -3.5941 & unstable \\
\hline$\Delta \operatorname{lnFR}$ & $(\mathrm{C}, 0,3)$ & -2.4345 & -3.7203 & -2.9848 & unstable \\
\hline$\Delta^{2} \operatorname{lnFR}$ & $(0,0,0)$ & -4.6146 & -2.6558 & -1.9548 & stationary \\
\hline $\ln \mathrm{UR}$ & $(\mathrm{C}, \mathrm{T}, 2)$ & -4.1758 & -4.3736 & -3.6026 & unstable \\
\hline$\Delta \ln \mathrm{NR}$ & $(\mathrm{C}, 0,3)$ & -2.4486 & -3.7345 & -2.9905 & unstable \\
\hline$\Delta^{2} \ln \mathrm{UR}$ & $(0,0,0)$ & -9.9783 & -2.6561 & -1.9543 & stationary \\
\hline
\end{tabular}


Note: $(\mathrm{C}, \mathrm{T}, \mathrm{K}), \mathrm{C}$ represents a constant term, $\mathrm{T}$ represents a trend term, $\mathrm{K}$ represents the number of delays, and $\mathrm{K}$ is determined by SIC criteria.

Since there are no unit roots for $\Delta^{2} \operatorname{lnFE}, \Delta^{2} \operatorname{lnFR}$ and $\Delta^{2} \operatorname{lnUR}$, and all are two order mono, so we establish the VAR (P) model. According to the minimum values of AIC and SIC, we set the lag value of each variable to 3 order, and the VAR (3) model is as follows:

$$
\Delta^{2} \operatorname{lnFR} t=-0.5928 \Delta^{2} \operatorname{lnFR}_{t-1}-0.9654 \Delta^{2} \operatorname{lnFR}_{t-2}-0.3644 \Delta^{2} \ln R_{t-3}
$$

$$
+0.5973 \Delta^{2} \ln \mathrm{FE}_{t-1}+0.8302 \Delta^{2} \operatorname{lnFE} E_{t-2}-0.0257 \Delta^{2} \operatorname{lnFE}{ }_{t-3}
$$

$$
+1.2092 \Delta^{2} \ln U R_{t-1}-0.5379 \Delta^{2} \ln U R_{t-2}-0.6123 \Delta^{2} \ln U R_{t-3}
$$

$$
(-0.6042)
$$

$$
\Delta^{2} \operatorname{lnFE} t=-0.0014 \Delta^{2} \operatorname{lnFR} R_{t-1}-0.7283 \Delta^{2} \operatorname{lnFR} R_{t-2}-0.2023 \Delta^{2} \ln F R_{t-3}
$$

$$
(-2.8981)
$$

$$
+0.2222 \Delta^{2} \operatorname{lnFE} t_{t-1}+0.3146 \Delta^{2} \operatorname{lnFE} t-2-0.0319 \Delta^{2} \operatorname{lnFE} t-3
$$

$$
+0.6563 \Delta^{2} \ln U R_{t-1}-0.5379 \Delta^{2} \ln U R_{t-2}-0.1300 \Delta^{2} \ln U R_{t-3}
$$

$$
\Delta^{2} \ln U R_{t}=-0.0097 \Delta^{2} \operatorname{lnFR} R_{t-1}-0.0919 \Delta^{2} \operatorname{lnFR}_{t-2}-0.0183 \Delta^{2} \ln R_{t-3}
$$

$$
(-1.0977)
$$

$$
-0.0196 \Delta^{2} \operatorname{lnFE} E_{t-1}+0.0872 \Delta^{2} \operatorname{lnFE} E_{t-2}+0.0431 \Delta^{2} \operatorname{lnFE} E_{t-3}
$$

$$
-0.4373 \Delta^{2} \ln U R_{t-1}+0.1757 \Delta^{2} \ln U R_{t-2}+0.3057 \Delta^{2} \ln U R_{t-3}
$$

$(0.7115)$

(1.5379) 


\subsection{Cointegration Test}

According to the analysis of this article, we have finally determined the lag number of 3 and set up the VEC model according to this. It is shown below.

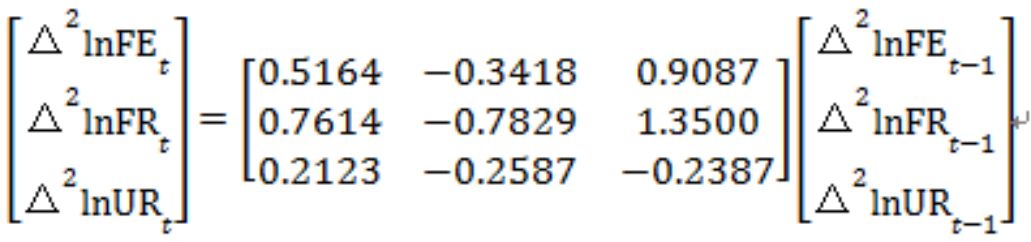

$$
\begin{aligned}
& +\left[\begin{array}{ccc}
0.4921 & -0.9554 & 0.6478 \\
0.9296 & -1.0925 & -0.4967 \\
0.2272 & -0.2709 & 0.2338
\end{array}\right]\left[\begin{array}{c}
\Delta^{2} \operatorname{lnFE} \\
{ }^{2}-2 \\
\Delta^{2} \operatorname{lnFR}{ }_{t-2} \\
\Delta^{2} \ln R_{t-2}
\end{array}\right]
\end{aligned}
$$

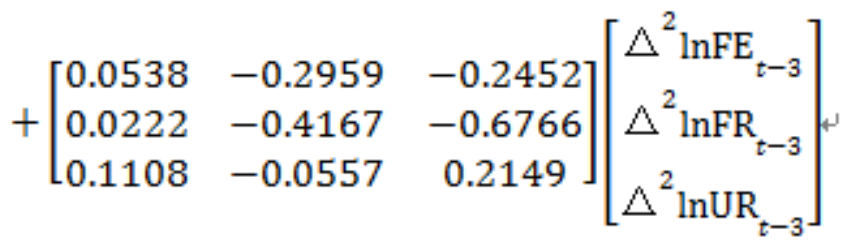

$$
\begin{aligned}
& +\left[\begin{array}{l}
-0.2459 \\
-0.1374 \\
-0.1938
\end{array}\right] \text { vecm }_{t-1}
\end{aligned}
$$

Therefore, according to the VEC model, the cointegration equation obtained is as follows.

$$
\triangle \operatorname{lnFE}{ }_{t}=-0.8553 \triangle \ln \ln _{t}+1.1446 \triangle \ln \mathrm{lR}_{t}-0.0603
$$

By testing the residuals of unit roots, a stable result can be obtained. Meanwhile, it proves that there is a long-range cointegration relationship between the three variables selected in this paper.

Table 2. unit root test results of sequence ECM

\begin{tabular}{l|l|l|l}
\hline ADF Test Statistic & -6.2813 & $1 \%$ critical value & -2.6522 \\
\hline & & $5 \%$ critical value & -1.9540 \\
\hline & & $10 \%$ critical value & -1.6223 \\
\hline
\end{tabular}

\subsection{Impulse Response Function}

In the VAR model, the impact of $i$ variable is not only directly affect $i$ variable, but also pass to other endogenous variables through the lagging structure of the VAR model. The impulse response function describes the influence of the impact of the random error term of a variable on the current and subsequent periods of each endogenous variable. Because there is a correlation between the random errors of different equations in VAR, an orthogonal matrix is needed to transform the impact of the same period into the same term. The specific decomposition diagram is as shown in Figure 1. Figure 1 shows the response of urbanization, fiscal revenue and fiscal expenditure to future information. 

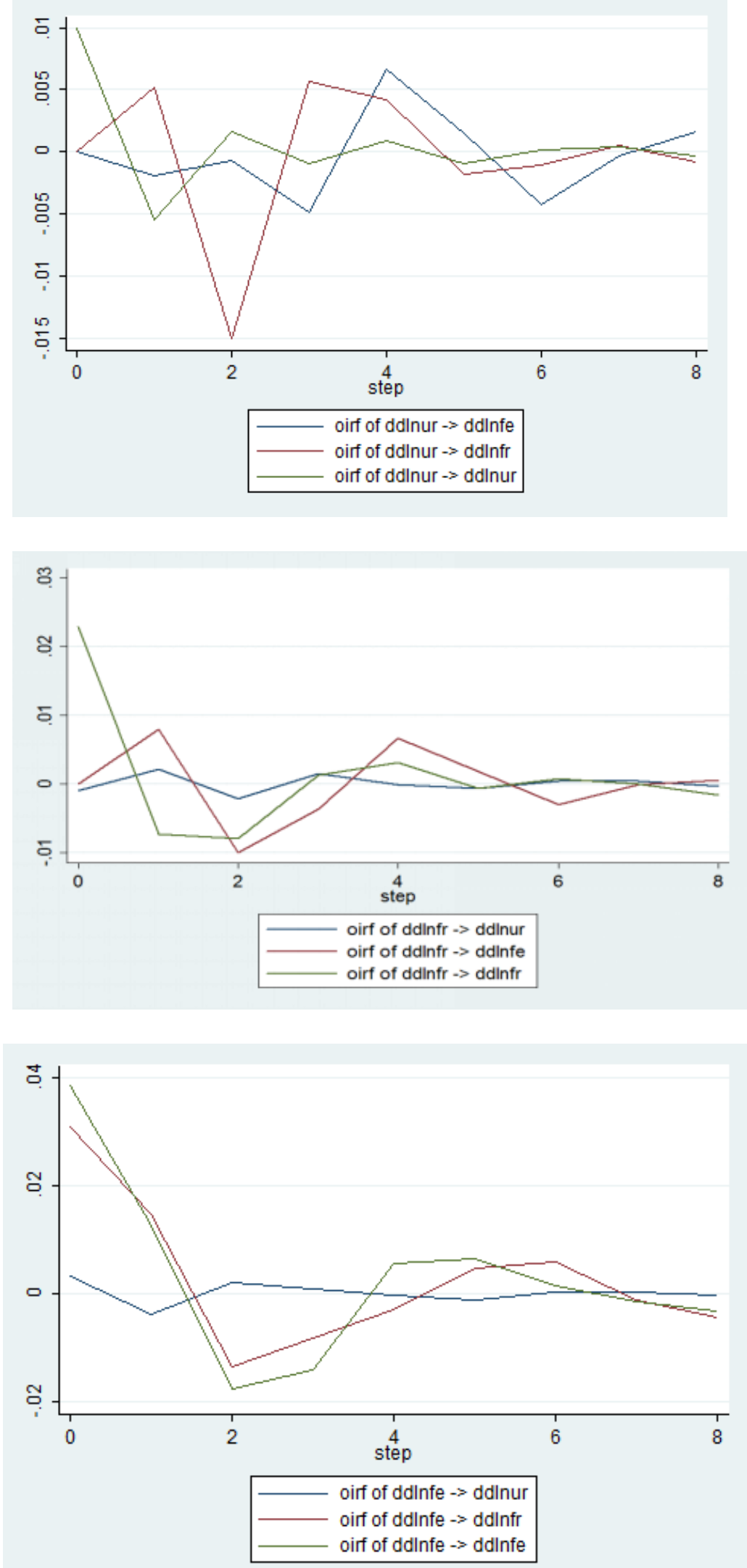

Figure 1. The response of urbanization, fiscal revenue and expenditure to external information 
The first picture shows the response of fiscal expenditure to urbanization and fiscal revenue. The standard deviation information of fiscal expenditure on itself has a greater response at the beginning and tends to slow gradually after the lag of the three phase. The impact of urbanization is not reflected in the first stage, and then the influence became larger, the fifth period reached the maximum, and the trend was mild after the sixth period. The impact of financial income is more significant in the third phase, and the fifth phase is smaller. It can be seen that the urbanization and fiscal revenue have a similar trend after the three period of fiscal expenditure lag.

The second picture shows the response of fiscal revenue to urbanization and fiscal expenditure. The standard deviation information of financial revenue has a strong reaction at the beginning. The impact of urbanization and fiscal expenditure has changed greatly in the early stage, and tends to be eased after the fourth period.

The third picture shows the response of urbanization to fiscal revenue and fiscal expenditure. The response of urbanization to its own standard deviation information is intense at the beginning. This process continues until the third stage, and gradually tends to slow after the lag of the three period. The influence has been reflected in the first period from the fiscal revenue. Until the fifth period, the positive and negative alternates are very obvious. The influence from the fiscal expenditure is the most significant in the fourth period, while the fifth period becomes negative. After the sixth period, it gradually becomes stable. It can be seen that there is a close relationship between urbanization and fiscal revenue and fiscal expenditure.

\subsection{Variance Decomposition}

When examining the VAR model, the variance decomposition method can also be used to study the dynamic characteristics of the model. The main idea is to decompose the fluctuation of each endogenous variable (M total) in the system into the $\mathrm{M}$ parts associated with each equation information (random error term) according to its causes, so as to understand the relative importance of each information to the endogenous variables of the system and estimate the delay effect of the variable size effect.

According to the influence of InFR and InFE on InUR, the variance decomposition of InUR is made (the result is shown in Table 4). By the decomposition of InUR, it can be seen that the standard deviation increases with the increasing of prediction, but the increase was not obvious. In the change of In UR, Components that are affected by their own perturbation impacts are less and less after the second period; The impact of fiscal revenue gradually increased, from $1.5 \%$ in the first period to $67.3 \%$ in the 10 th period, of which $4.2 \%$ in the fourth period suddenly rose to $11.8 \%$ in the fifth period; the impact of fiscal expenditure on In UR was also significant. However, there is a gradual decrease trend and it appears after the fifth period. As a whole, the share of finance in the proportion is high, so it is an important variable.

From the delay effect of view, the two variables have a more sustained stimulating effect on urbanization. From the point of view, In the process of pulling urbanization, the short-term fiscal policy on Urbanization in fiscal expenditure is better than revenue, but in the long term, the promotion of fiscal policy to urbanization requires a more long-term process of gradual increase.

Table 3. lnUR variance test

\begin{tabular}{l|l|l|l|l}
\hline period & $\begin{array}{l}\text { standard } \\
\text { deviation }\end{array}$ & $\operatorname{lnUR}$ & $\operatorname{lnFR}$ & $\operatorname{lnFE}$ \\
\hline 1 & 0.029940 & 77.53535 & 1.49082 & 20.97383 \\
\hline 2 & 0.062012 & 75.94622 & 0.69144 & 23.36234 \\
\hline 3 & 0.083026 & 67.76421 & 0.93345 & 31.30235 \\
\hline 4 & 0.093446 & 57.07190 & 4.23682 & 38.69129 \\
\hline 5 & 0.104135 & 46.38616 & 11.82231 & 41.79153 \\
\hline 6 & 0.120503 & 37.16641 & 24.03385 & 38.79975 \\
\hline 7 & 0.139797 & 29.81456 & 38.98831 & 31.19713 \\
\hline 8 & 0.160283 & 24.54340 & 52.31358 & 23.14302 \\
\hline 9 & 0.182202 & 21.17756 & 61.51550 & 17.30695 \\
\hline 10 & 0.206055 & 19.08250 & 67.27409 & 13.64341 \\
\hline
\end{tabular}




\section{Conclusions and Suggestions}

\subsection{Research Conclusions}

(1) There is a cointegration relationship between fiscal policy and urbanization

From the previous data, we can see that there is a long-term cointegration relationship between the three variables of Jiangxi's fiscal revenue and fiscal expenditure and the urbanization rate. Fiscal revenue and fiscal expenditure actually represent fiscal policy. Although this is only part of the fiscal policy, it can be quantified, but this does not affect the conclusion of our research. There is an interrelated relationship between fiscal policy and urbanization. First, from the system level, the current fiscal policy, make regional and local market power of urbanization development; second is the investment environment of Jiangxi Province, in recent years, relying on the center of the city and an important node in the city, the traffic channel for the main axis, the initial formation of the "urban layout backbone area three" group two, namely Poyang Lake eco city group, the Shanghai Kunming along the Urban Development Zone, jingjiuyanxian Town Development Zone, Ganzhou, Jiujiang and Nanchang metropolitan area, metropolitan area, metropolitan area, the guiding role of fiscal policy is obvious. Under the layout of these cities and towns, the investment environment in Jiangxi has been improved and the investment amount has been greatly improved. From 1979 to 2014, the average growth rate of $23.3 \%$ of the total investment, the average total investment in fixed assets in the last ten years the average growth rate is maintained at a high level in $28.1 \%$, the new increase in the growth rate of fixed asset investment in the $24.8 \%$ level; finally the fiscal policy of Jiangxi Province population transfer has great effect.

Table 4. Changes in total investment in Jiangxi Province over the years

\begin{tabular}{|c|c|c|c|c|c|c|c|}
\hline \multirow[b]{2}{*}{ time } & \multicolumn{4}{|c|}{ Total amount (billion yuan) } & \multicolumn{3}{|c|}{ Average growth rate $(\%)$} \\
\hline & 1990 & 2000 & 2013 & 2014 & $\begin{array}{c}1979 \\
-2014\end{array}$ & $\begin{array}{c}1991 \\
-2014\end{array}$ & $\begin{array}{l}2001 \\
-2014\end{array}$ \\
\hline Total investment & 70.65 & 548.2 & 7164.62 & 12850.25 & 23.3 & 25.5 & 28.1 \\
\hline New fixed assets & 32.5 & 453.31 & 4739.38 & 8328.46 & & 27 & 24.8 \\
\hline
\end{tabular}

(2) There is a close relationship between urbanization and Finance

The relationship between fiscal policy and urbanization was originally interrelated. The construction of urbanization in Jiangxi has also promoted the more rational and scientific financial policy. Because of the urbanization, the population concentration of Jiangxi province is increasing. This will narrow the scope of financial services in Jiangxi Province, and make the public services provided by the finance more precise and precise. Jiangxi Provincial Social Science Research Group (2012) ${ }^{7}$ surveyed the urbanization situation in Jiangxi Province, and thought that in the past 2007-2012 years, the urban population in Jiangxi increased by nearly 4 million times, and the urbanization rate increased by 1.5 percentage points per year. In 2012, there were 7 large cities with a population of 500 thousand 100 million in Jiangxi Province, namely, Jiujiang, Shangrao, Fuzhou, Pingxiang, Ji'an, Ganzhou and Jingdezhen. The gathering of population can make Jiangxi improve the quality of public services and reduce the cost of public services at the limited level of fiscal expenditure.

\section{(3) Fiscal expenditure has a greater impact on Urbanization}

In our research results, the impact of fiscal expenditure on the urbanization of Jiangxi province is better than the fiscal revenue. This is a more normal form. Compared with the eastern provinces or even the other provinces in the central part, the urbanization level of Jiangxi is not enough. There is still much room for improvement. This requires Jiangxi to provide more support for urbanization in terms of fiscal expenditure. In 2011, the urbanization rate of the six provinces in Central China were 49.7\% in Shanxi Province, $44.8 \%$ in Anhui Province, $45.7 \%$ in Jiangxi Province, $40.6 \%$ in Henan Province, $51.8 \%$ and $45.1 \%$ in Hubei province. At present, there are still many areas for improvement in Jiangxi's urbanization rate and financial support. Therefore, the impact of fiscal expenditure on Urbanization in Jiangxi is more significant.

\footnotetext{
${ }^{7}$ Wei Houkai. Research on the strategic evaluation and policy adjustment of the rise of central China to Jiangxi province. Beijing: Economic Management Press.
} 


\subsection{Policy Recommendations}

First, the financial fund guarantee mechanism of the new urbanization.

\subsubsection{Construct the Financial Transfer Payment System Based on the Standard of Public Service}

The basis of the financial transfer payment for the purpose of promoting urbanization should be the level of public service. According to the actual conditions of the world, the establishment of public service standards can be divided into five grades. This is followed by the general urban division of the four level, while the town is level fifth. They are class a cities (north to Guangzhou and Shenzhen), B class cities (developed provincial capitals), C cities (underdeveloped provincial capitals and districts), D cities (county-level cities, counties and town level cities) and townships and other five levels. The subsidy standard of the financial transfer payment should be the higher the lower level of the subsidy, the less the higher the level of the subsidy. The formula of subsidy for financial transfer payment can be formulated by the linear subsidy formula of negative income tax. The key to the design of this system is to determine the minimum per capita standard of per capita fiscal revenue and the financial ratio of the central government to the central finance.

\subsubsection{Construction of Financial Investment and Financing System Based on Local Government Bonds}

The scale of capital needed for urbanization is far greater than financial financial resources. In the process of further implementation of the hardware construction of urbanization, local governments apply the model of PPP and other private capital into the construction of hardware facilities.

To encourage investment in urban construction and infrastructure construction, the joint efforts of the government and the social forces are needed.

The second, the financial policy of the industrial development of the new urbanization.

(1) fiscal policy creates a good environment for Urbanization

(2) government guarantees the lowest possible financial and tax cost environment

(3) guarantee a fair competitive environment

Last, the public finance policy of Urbanization.

(1) promoting the integration of urban and rural areas

(2) promoting the reform of land use system

(3) financial support for public participation in public services.

\section{Acknowledgements}

1. The author acknowledges the financial support from Modern Economics\&Management College, Jiangxi University of Finance and Economic (YJKT-14-2).

2. The author acknowledges the financial support from Science and Technology Fund Project of the Education Department of Jiangxi Province (GJJ161550).

\section{References}

Lei Yuyu, \& Gong Liutang. (2014). The effect of urbanization on residents' consumption rate: theoretical model and empirical analysis[J]. Economic Research, 06, 44-57.

Li Zilian. (2013). The mystery of Population urbanization lagging behind land urbanization: Explanation from China's provincial panel data. [J]. China's population, resources and environment, 11, 94-101.

Liu Jinquan, Yin Zhong, \& Pang Chunyang. (2014). Research on the effectiveness of China's active fiscal policy and the period structure of policy [J]. China industrial economy, 06, 31-43.

Ma Xiao Xian. (2014). Analysis of the key factors and effects of urbanization in China [J]. China's population, resources and environment, 12, 17-124.

Wei Houkai. Research on the strategic evaluation and policy adjustment of the rise of central China to Jiangxi province. Beijing: Economic Management Press. 
Xu Xianchun, Wang Baobin, \& Xu Xiongfei. (2013). China's investment growth and its relationship with fiscal policy [J]. Management World, 06, 1-11.

Zhu Jialiang, \& Zhang Yang. (2015). An empirical study on the relationship between urbanization process and fiscal policy in China [J]. China price, 01, 32-35.

\section{Copyrights}

Copyright for this article is retained by the author(s), with first publication rights granted to the journal.

This is an open-access article distributed under the terms and conditions of the Creative Commons Attribution license (http://creativecommons.org/licenses/by/4.0/). 